Kodifikasia : Jurnal Penelitian Islam, Vol 14, No. 01 (2020), 195-212

DOI : 10.21154/kodifikasia.v14i1.1937

ISSN : 1907-6371 (Cetak)

ISSN : 2527-9254 (Online)

\title{
INDEKS DIMENSI MAKRO BAZNAS KOTA MATARAM BERDASARKAN INDEKS ZAKAT NASIONAL
}

\author{
Ahmad Sidi Pratomo*, Shulhan Zainul Afkar*
}

\begin{abstract}
ABSTRAK:
Kemiskinan menjadi permasalahan umum di negara berkembang, termasuk di Indonesia. Bagi umat islam, zakat merupakan instrumen pengentas kemiskinan. Indonesia sebagai salah satu negara dengan penduduk muslim terbesar, perlu peran penting antara pemerintah dan lembaga zakat untuk melakukan penghimpunan lebih masif. Beberapa daerah sudah memiliki Peraturan Daerah tentang pengelolaan zakat, salah satunya di BAZNAS Kota Mataram. PUSKASBAZNAS mengeluarkan indeks untuk mengukur kinerja perzakatan secara nasional maupun regional. Dimensi Makro pada Indeks Zakat Nasional digunakan untuk mengukur kinerja perzakatan dalam peran pemerintah dan masyarakat untuk mengembangkan lembaga zakat. Penelitian ini menggunakan pendekatan mixed methods dengan melakukan wawancara terhadap pimpinan BAZNAS Kota Mataram, kemudianmenentukan nilai indeks Dimensi Makro dengan menggunakan Multistage Weigh Index. Berdasarkan data wawancara yang didapat, BAZNAS Kota Mataram memiliki Peraturan Daerah tentang Pengelolaan Zakat, Infaq dan Sedekah, shingga indikator regulasi mendapatkan nilai indeks 1 yang berarti sangat baik. BAZNAS Kota Mataram juga mendapatkan dukungan APBD sebesar Rp 600 juta untuk biaya operasional, sehingga mendapatkan nilai indeks 0,5 yang berarti kinerjanya adalah baik, dan terakhir pada indikator database mendapat nilai indeks 0,33 yang berarti kinerja indikator ini adalah baik. Kinerja BAZNAS Kota Mataram berdasarkan Indeks Dimensi Makro pada Indeks Zakat Nasional adalah cukup baik dengan nilai indeks 5,99.
\end{abstract}

Kata Kunci: Kinerja BAZNAS; Dimensi Makro; Indeks Zakat Nasional

*Hukum Bisnis Syariah UIN Maulana Malik Ibrahim Malang, email: mr.mandiri@ gmail.com

** Ekonomi Syariah Pascasarjana UIN Maulana Malik Ibrahim Malang, email: shulhanzain@gmail.com 


\begin{abstract}
:
Poverty becomes a common problem in developing countries, including in Indonesia. For Muslims, zakat is a poverty alleviation instrument. Indonesia as one of the countries with the largest Muslim population needs an important role between the government and the zakat institution to conduct a more massive gathering. One of them already has a Regional Regulation on the management of zakat to optimize the collection of zakat, one of them is BAZNAS in Mataram City. PUSKAS BAZNAS issued an index to measure the performance of national and regional zakat. The Macro Dimension of the National Zakat Index is used to measure the performance of zakat in terms of the role of the government and society to develop zakat institutions. This study uses qualitative interviews with the leaders of BAZNAS in Mataram city, then Macro Dimension index value is determined using the Multistage Weigh Index. Based on the interview data obtained that BAZNAS in Mataram has Regional Regulations concerning Management of Zakat, Infaq and Alms, so that the regulatory indicators get an index value of 1 which means very good. BAZNAS of Mataram city received APBD support of Rp. 600 million for operational costs, so this indicator gets an index value of 0.5 which means its performance is good, and finally the database indicator gets an index value of 0.33 which means the performance this is good. The performance of BAZNAS in Mataram City based on the Macro Dimension Index on National Zakat Index is quite good with an index value of 5.99.
\end{abstract}

Keywords: BAZNAS Performance; Macro Dimension; National Zakat Index.

\title{
PENDAHULUAN
}

Kemiskinan menjadi sebuah permasalahan di setiap negara, terlebih lagi bagi negara kecil dan berkembang, termasuk negara Indonesia. Menurut data Badan Pusat Statistik, pada Maret 2019 tingkat kemiskinan Indonesia berada pada titik 9,41\% atau sebesar 25,14 juta jiwa. ${ }^{1}$ Sedangkan Kota Mataram tercatat pada Maret 2019 ada sekitar 43.190 jiwa penduduk miskin dengan garis kemiskinan Rp 480.304. ${ }^{2}$ Indonesia juga dikenal sebagai

${ }^{1}$ Badan Pusat Statistik, "Persentase Penduduk Miskin Maret 2019 Sebesar 9,41 Persen,” diakses 20 April 2020,https://www.bps.go.id/pressrelease/2019/07/15/1629/ persentase-penduduk-miskin-maret-2019-sebesar-9-41-persen.html.

${ }^{2}$ Badan Pusat Statistik Kota Mataram"Kota Mataram, Maret 2019: Persentase Penduduk Miskin sebesar 8,92 Persen,” diakses 20 April 2020, https://mataramkota.bps.

Kodifikasia: Jurnal Penelitian Islam, Volume, 14 No. 1 Tahun 2020 
salah satu negara dengan jumlah penduduk muslim terbesar di dunia, tingginya jumlah penduduk muslim di Indonesia tentu memiliki potensi penghimpunan zakat yang besar. Sebuah penelitian yang dilakukan oleh Sudibyo (2018), menyebutkan potensi penghimpunan zakat di Indonesia secara nasional pada tahun 2017 dapat mencapai Rp 462 triliun. Namun BAZNAS (2018) mencatat penghimpunan zakat, infaq dan sedekah hanya Rp 6,2 triliun pada tahun $2017 .^{3}$

Tingginya potensi zakat di Indonesia saat ini belum bisa menurunkan tingkat kemiskinan secara signifikan, karena adanya gap yang cukup tinggi antara potensi dengan realisasi penghimpunan zakat. Dalam Islam, zakat dikenal sebagai instrumen pendistribusian harta yang dapat meminimalisir kemiskinan. Di Al-Qur'an telah dijelaskan tentang wajib zakat terletak pada Surat At-Taubah ayat 103 yang artinya "Ambillah zakat dari sebagian harta mereka, dengan zakat itu kamu membersihkan dan mensucikan mereka dan berdoalah untuk mereka.". hal tersebut juga diperkuat dengan hadits dari Ibnus Abbas yang artinya "Dari Ibnu Abbas ra. bahwa Nabi SAW mengutus Mu'adz ke negeri Yaman --ia meneruskan hadits itu-- dan di dalamnya (Beliau bersabda): "Sesungguhnya Allah telah mewajibkan mereka zakat dari harta mereka yang diambil dari orang-orang kaya di antara mereka dan dibagikan kepada orang-orang fakir di antara mereka." (Muttafaq Alaihi dan lafadznya menurut Bukhari)

Dalam hal ini, berdasarkan UU Nomor 23 tahun 2011 tentang Pengelolaan Zakat, Indonesia memiliki lembaga pengelola zakat yang mengumpulkan, mengelola dan menyalurkan zakat, yaitu BAZNAS dan LAZ. BAZNAS adalah lembaga pengelola zakat yang dibentuk oleh pemerintah, dan LAZ merupakan lembaga yang dibentuk oleh masyarakat atau swasta yang bergerak dibidang dakwah, pendidikan, sosial dan kemaslahatan umat. ${ }^{4}$ BAZNAS Kota Mataram sebagai lembaga yang berwenang mengelola dana zakat, infaq dan sedekah, berorientasi untuk menyelesaikan masalah kemiskinan dengan cara memandirikan mustahiq dan amil di Kota Mataram.

Menurut Mahsar Malacca, selaku ketua BAZNAS Kota Mataram, potensi ZIS yang ada di Kota Mataram mencapai Rp 16 miliar, namun tahun

$\overline{\text { go.id/pressrelease }} / 2019 / 12 / 16 / 301 /$ kota-mataram--maret-2019--persentase-pendudukmiskin-sebesar-8-92-persen.html.

3 BAZNAS Center of Strategic Studies, "Outlook Zakat Indonesia 2019," BAZNAS Center of Strategic Studies, 1-2, diakses 18 Februari 2020, https://www.puskasbaznas.com/ publications/outlook/indonesia-zakat-outlook-2019/887-outlook-zakat-indonesia-2019.

${ }^{4}$ Undang-Undang Republik Indonesia Nomor 23 tahun 2011 tentang Pengelolaan Zakat, (Jakarta, 2011). 
2018 ini hanya bisa menghimpun sekitar 40\%. ${ }^{5}$ Kota Mataram dengan tingkat PDRB tahun 2016 sebesar Rp 13,22 triliun $^{6}$ dan jumlah penduduk muslim 344.448 jiwa $^{7}$ harusnya bisa mencapai target tersebut. Perlu diketahui, bahwa Pemerintah Kota Mataram sudah mengeluarkan Peraturan Daerah tentang pengelolaan zakat di kota Mataram, dan memberikan alokasi APBD untuk program dan operasional yang cukup besar kepada BAZNAS Kota Mataram. Memang perlu adanya kerjasama yang baik antara pemerintah, masyarakat dan lembaga zakat dalam meningkatkan kesadaran masyarakat untuk membayar zakat.

Pada penelitian ini, penulis ingin melihat bagaimana kinerja perzakatan di Kota Mataram yang mencakup peran pemerintah dan lembaga zakat berdasarkan Indeks Zakat Nasional yang dikembangkan oleh Pusat Kajian Strategi BAZNAS tahun 2016. Sebelum adanya IZN, Abdullahet al (2012) telah mencoba mengusulkan alat ukur perzakatan berupa zakat effectiveness index yang mengukur sejauh mana peran pemerintah untuk mengalokasikan anggaran terhadap penerima zakat. ${ }^{8}$ Selain itu, Beik juga melakukan penelitian terkait dampak zakat yang dapat dilihat dari ukuran standar kemiskinan di Badan Pusat Statistik. Riset ini dilanjutkan dan disempurnakan dengan memasukkan variabel spiritual yang kemudian disebut CIBEST. $^{9}$ Di sisi lain, Nurzaman juga melakukan riset yang mengukur bagi kesejahteraan rumah tangga mustahik dengan memodifikasi Indeks Pembangunan Manusia. ${ }^{10}$

Indeks Zakat Nasional merupakan indeks atau alat ukur untuk mengukur kinerja dan perkembangan perzakatan secara nasional maupun regional. Indeks ini dapat diaplikasikan oleh BAZNAS dan LAZ di tingkat nasional, maupun di tingkat daerah sehingga setiap instansi zakat mempunyai standar mutu yang berkualitas. Indeks Zakat Nasional terdiri

\footnotetext{
${ }^{5}$ Gita Amanda, “Baznas: Potensi ZIS Mataram Capai Rp 16 Miliar,” Republika.co.id, February8, 2018, Khazanah

${ }^{6}$ Badan Pusat Statistik Kota Mataram, "PDRB atas Dasar Harga Berlaku 2010-2016" (Mataram, 2017), https://mataramkota.bps.go.id/dynamictable/2017/07/05/298/pdrbkota-mataram-atas-dasar-harga-konstan-2010-menurut-lapangan-usaha-2010-2016.html.

7 Dinas Komunikasi dan Informatika Kota Mataram, "Kota Mataram dalam Data 2018" (Mataram, 2018).

${ }^{8}$ Naziruddin Abdullah, Mohd Mahyudi Mohd Yusop, dan Che Omar Hj Awang, "A Technical Note on The Derivation of Zakat Effectiveness Index (Zein)," International Journal of Economics, Management and Accounting 20, no. 1 (2012), https://journals.iium. edu.my/enmjournal/index.php/enmj/article/view/188.

${ }^{9}$ Irfan Syauqi Beik dan Laily Dwi Arsyianti, "Measuring Zakat Impact On Poverty And Welfare Using Cibest Model," Journal of Islamic Monetary Economics and Finance 1, no. 2 (29 Februari 2016): 141-60, https://doi.org/10.21098/jimf.v1i2.524.

${ }^{10}$ Mohammad Soleh Nurzaman, "Evaluating the Impact of Productive Based Zakat in The Perspective of Human Development Index: A Comparative Analysis," Kyoto Bulletin of Islamic Area Studies 9, no. 29 (2016): 42-62.
} 
dari dimensi makro dan dimensi mikro. Dimensi makro membahas terkait regulasi zakat di daerah, dukungan APBD terhadap lembaga zakat, dan ketersediaan database pada lembaga zakat. Sedangkan dimensi mikro membahas terkait kelembagaan dari sisi penghimpunan, pengelolaan, penyaluran dan pelaporan, serta membahas dampak zakat. ${ }^{11}$

Penelitian sebelumnya dilakukan oleh Farchatunnisa (2017) yang mengukur kinerja BAZNAS Kota Bandung dengan menggunakan Indeks Zakat Nasional.Hasilnya menyebutkan bahwa indeks dimensi makro Kota Bandung adalah 0,047, karena di Kota Bandung belum memiliki Peraturan Daerah tentang Pengelolaan Zakat dan tidak adanya dukungan APBD untuk operasional BAZNAS Kota Bandung. ${ }^{12}$ Khoirunnisa (2017) juga melakukan penelitian tentang kinerja BAZNAS Kabupaten Cilacap. Hasilnya menyebutkan nilai indeks dimensi makronya adalah 0,274 yang berarti kurang baik, karena Kabupaten Cilacap belum memiliki Perda zakat, dan jumlah muzaki individu terhadap rumah tangga kabupaten kurang dari $1 \%$ serta jumlah muzaki badan terhadap badan usaha kurang dari $1 \%{ }^{13}$

Widiawatiet al (2017) juga meneliti Indeks Zakat Nasional pada BAZNAS Provinsi Jawa Barat. Hasilnya menunjukkan bahwa BAZNAS Provinsi Jawa Barat memiliki Perda Zakat dan memiliki nilai indeks 1 yang berarti sangat baik. Namun pada dukungan APBD mendapat nilai indeks 0 karena rasio alokasi APBD terhadap pembiayaan operasional BAZNAS Provinsi Jawa Barat hanya mencapai $11,5 \%$ dan pada indeks database mendapat nilai 0,2475 yang mengindikasikan sangat lemah. Maka nilai indeks dimensi makro pada kinerja perzakatan Provinsi Jawa Barat adalah 0,3745 yang berarti kinerja BAZNAS Provinsi Jawa Barat dalam kategori kurang baik..$^{14}$

Di sisi lain, Hilmiyah juga melakukan penelitian untuk melihat kinerja perzakatan di Kabupaten Bogor dengan menggunakan Indeks Zakat Nasional. Hasilnya indeks dimensi makro mendapatkan nilai indeks 0,40 yang berarti kinerja perzakatan dari sisi makro yang melibatkan pemerintah dan partisipasi masyarakat kurang baik. Indeks pada indikator regulasi adalah nol karena tidak memiliki Perda Zakat, sedangkan indikator

${ }^{11}$ Pusat Kajian Strategis Badan Amil Zakat Nasional, "Indeks Zakat Nasional" (Jakarta, 2016), http://puskasbaznas.com/indonesia-zakat-index/national-zakat-index/nzi/ download/70-nzi.

${ }^{12}$ Hidayaneu Farchatunnisa, "Analisis Kinerja Baznas Kota Bandung Dengan Pendekatan Indeks Zakat Nasional” (IPB Bandung, 2017), 71.

${ }^{13}$ Ayu Amalia Khoirunnisa, "Analisis Kinerja Baznas Kabupaten Cilacap Dengan Pendekatan Indeks Zakat Nasional" (IPB Bogor, n.d.), 72.

${ }^{14}$ Nunung Nurhayati Widiawati dan Ifa Hanifa Senjiati, "Kinerja Pengelolaan Zakat Menggunakan Indeks Zakat Nasional (IZN) di Baznas Provinsi Jawa Barat,” Prosiding Hukum Ekonomi Syariah 4(1) (2018): 308-14. 
dukungan APBD mendapatkan nilai indeks satu dan pada indikator database mendapat nilai indeks nol. ${ }^{15}$

Paparan di atas melatarbelakangi peneliti untuk memfokuskan pembahasan pada indeks dimensi makro menggunakan Indeks Zakat Nasional, yang membahas tentang kinerja perzakatan pada indikator regulasi atau perda zakat, dukungan APBD untuk lembaga zakat, dan database lembaga zakat di BAZNAS Kota Mataram. Menarik untuk dibahas karena tidak cukup hanya peran pemerintah saja dalam pengembangan zakat berupa penerapan Perda, namun juga harus ada kesadaran dari masyarakat untuk membayar zakat agar dapat meningkatkan penghimpunan zakat.

Penelitian ini nantinya diharapkan dapat menjadi rujukan BAZNAS Kota Mataram dalam melakukan pengembangan program dan menjadi bahan evaluasi. Selain itu penelitian ini merupakan salah satu upaya untuk mengimplementasikan indeks perzakatan yang dikembangkan oleh PUSKAS BAZNAS dan menjadi bahan pertimbangan dalam melakukan pengembangan sistem pengentasan kemiskinan di Indonesia melalui zakat.

Penelitian ini menggunakan jenis penelitian Mixed Methods. Dalam kajian ini, metode kualitatif digunakan untuk memaparkan data-data faktual dari hasil wawancara yang diperoleh dari pengurus BAZNAS Kota Mataram, sedangkan metode kuantitatif digunakan untuk menampilkan data hasil perhitungan Indeks Zakat Nasional. Penelitian ini menggunakan jenis data primer dan data sekunder. Data primer diperoleh dari proses wawancara dengan para pimpinan dan pegawai yang ada di BAZNAS Kota Mataram. Kemudian data sekunder merupakan data yang didapatkan dari sumber literatur atau dokumen-dokumen yang terpublikasi atau tidak pada media cetak maupun media online. ${ }^{16}$

Adapun tahapan penghitungan indeks dimensi makro dilakukan sebagai berikut.

1. Membuat skoring pada setiap variabel dengan rentang 1-5, berdasarkan kondisi aktual di lapangan yang didapat dari hasil wawancara. Skor 1 berarti sangat lemah, hingga skor 5 berarti sangat kuat.

${ }^{15}$ Ulfah Laelatul Hilmiyah, "Analisis Kinerja Perzakatan BAZNAS Kabupaten Bogor" (IPB Bogor, 2017).

${ }^{16}$ Pusat Kajian Strategis Badan Amil Zakat Nasional, "Indeks Zakat Nasional." 
Tabel 1.

Skoring Dimensi Makro

\begin{tabular}{|c|c|c|c|c|c|c|}
\hline \multirow[t]{2}{*}{ No } & \multirow[t]{2}{*}{ Variabel } & \multicolumn{5}{|c|}{$\begin{array}{c}\text { Kriteria } \\
(1=\text { sangat lemah, } 2=\text { lemah, } 3=\text { cukup, } 4=\text { kuat, } 5=\text { sangat } \\
\text { kuat })\end{array}$} \\
\hline & & 1 & 2 & 3 & 4 & 5 \\
\hline 1 & Regulasi & \multicolumn{5}{|c|}{$\begin{array}{l}\text { Karena yang diteliti ruang lingkupnya Kota, maka jika suatu } \\
\text { daerah memiliki Peraturan Daerah terkait pengelolaan zakat, } \\
\text { secara otomatis diberikan skor } 5 \text {, jika tidak memiliki Perda } \\
\text { Zakat diberikan skor } 1 \text {. }\end{array}$} \\
\hline 2 & $\begin{array}{l}\text { Duku } \\
\text { ngan } \\
\text { APBD }\end{array}$ & $\begin{array}{l}\text { Rasio total } \\
\text { alokasi APBD } \\
\text { terhadap } \\
\text { biaya op- } \\
\text { erasional BA- } \\
\text { ZNAS }<20 \%\end{array}$ & \begin{tabular}{|l|} 
Rasio total \\
alokasi APBD \\
terhadap \\
biaya op- \\
erasional \\
BAZNAS \\
sekurang- \\
kurangnya \\
20\%
\end{tabular} & \begin{tabular}{|l|} 
Rasio total \\
alokasi APBD \\
terhadap \\
biaya op- \\
erasional \\
BAZNAS \\
sekurang- \\
kurangnya \\
$30 \%$
\end{tabular} & \begin{tabular}{|l|} 
Rasio total \\
alokasi APBD \\
terhadap \\
biaya op- \\
erasional \\
BAZNAS \\
sekurang- \\
kurangnya \\
$50 \%$
\end{tabular} & $\begin{array}{l}\text { Rasio total } \\
\text { alokasi APBD } \\
\text { terhadap } \\
\text { biaya op- } \\
\text { erasional } \\
\text { BAZNAS } \\
\text { sekurang- } \\
\text { kurangnya } \\
75 \%\end{array}$ \\
\hline 3 & $\begin{array}{l}\text { Jumlah } \\
\text { lembaga } \\
\text { zakat } \\
\text { resmi, } \\
\text { muzaki } \\
\text { dan } \\
\text { mustahik }\end{array}$ & \begin{tabular}{|l|} 
Tidak memi- \\
liki database \\
dari jumlah \\
lembaga zakat \\
resmi, jumlah \\
muzaki dan \\
mustahik per \\
lembaga
\end{tabular} & \begin{tabular}{|l|} 
Memiliki 1 \\
dari database \\
jumlah lem- \\
baga zakat \\
resmi, jumlah \\
muzaki dan \\
mustahik per \\
lembaga
\end{tabular} & $\begin{array}{l}\text { Memiliki } 2 \\
\text { dari database } \\
\text { jumlah lem- } \\
\text { baga zakat } \\
\text { resmi, jumlah } \\
\text { muzaki dan } \\
\text { mustahik per } \\
\text { lembaga }\end{array}$ & $\begin{array}{l}\text { Memiliki } \\
\text { database } \\
\text { jumlah lem- } \\
\text { baga zakat } \\
\text { resmi, jumlah } \\
\text { muzaki dan } \\
\text { mustahik per } \\
\text { lembaga }\end{array}$ & $\begin{array}{l}\text { Memiliki } \\
\text { database } \\
\text { jumlah lem- } \\
\text { baga zakat } \\
\text { resmi, jumlah } \\
\text { muzaki dan } \\
\text { mustahik per } \\
\text { lembaga serta } \\
\text { peta perseba- } \\
\text { rann ya }\end{array}$ \\
\hline 4 & $\begin{array}{l}\text { Rasio } \\
\text { jumlah } \\
\text { muzaki } \\
\text { individu } \\
\text { terhadap } \\
\text { jumlah } \\
\text { rumah } \\
\text { tangga }\end{array}$ & $\begin{array}{l}\text { Rasio jumlah } \\
\text { muzaki ter- } \\
\text { daftar (memi- } \\
\text { liki NPWZ) } \\
\text { terhadap } \\
\text { rumah tangga } \\
<1 \%\end{array}$ & \begin{tabular}{|l|} 
Rasio jumlah \\
muzaki ter- \\
daftar (memi- \\
liki NPWZ) \\
terhadap \\
rumah tangga \\
$1-3.9 \%$
\end{tabular} & $\begin{array}{l}\text { Rasio jumlah } \\
\text { muzaki ter- } \\
\text { daftar (memi- } \\
\text { liki NPWZ) } \\
\text { terhadap } \\
\text { rumah tangga } \\
4-6,9 \%\end{array}$ & $\begin{array}{l}\text { Rasio jumlah } \\
\text { muzaki ter- } \\
\text { daftar (memi- } \\
\text { liki NPWZ) } \\
\text { terhadap } \\
\text { rumah tangga } \\
7-10 \%\end{array}$ & $\begin{array}{l}\text { Rasio jumlah } \\
\text { muzaki ter- } \\
\text { daftar (memi- } \\
\text { liki NPWZ) } \\
\text { terhadap } \\
\text { rumah tangga } \\
>10 \%\end{array}$ \\
\hline 5 & $\begin{array}{l}\text { Rasio } \\
\text { jumlah } \\
\text { muzaki } \\
\text { badan } \\
\text { terhadap } \\
\text { jumlah } \\
\text { badan } \\
\text { usaha }\end{array}$ & $\begin{array}{l}\text { Rasio jum- } \\
\text { lah muzaki } \\
\text { badan terdaf- } \\
\text { tar (memiliki } \\
\text { NPWZ) ter- } \\
\text { hadap jumlah } \\
\text { badan usaha } \\
<1 \%\end{array}$ & \begin{tabular}{|l|} 
Rasio jum- \\
lah muzaki \\
badan terdaf- \\
tar (memiliki \\
NPWZ) ter- \\
hadap jumlah \\
badan usaha \\
$1-1,9 \%$
\end{tabular} & $\begin{array}{l}\text { Rasio jum- } \\
\text { lah muzaki } \\
\text { badan terdaf- } \\
\text { tar (memiliki } \\
\text { NPWZ) ter- } \\
\text { hadap jumlah } \\
\text { badan usaha } \\
2-2,9 \%\end{array}$ & $\begin{array}{l}\text { Rasio jum- } \\
\text { lah muzaki } \\
\text { badan terdaf- } \\
\text { tar (memiliki } \\
\text { NPWZ) ter- } \\
\text { hadap jumlah } \\
\text { badan usaha } \\
3-3,9 \%\end{array}$ & $\begin{array}{l}\text { Rasio jum- } \\
\text { lah muzaki } \\
\text { badan terdaf- } \\
\text { tar (memiliki } \\
\text { NPWZ) ter- } \\
\text { hadap jumlah } \\
\text { badan usaha } \\
\geq 4 \%\end{array}$ \\
\hline
\end{tabular}

Sumber: Data diolah peneliti dari PUSKAS BAZNAS, 2019

2. Tahap selanjutnya adalah menghitung indeks setiap variabel. Rumus untuk menghitung indeks pada setiap variabel adalah sebagai berikut: 
$\mathrm{I}_{\mathrm{i}}=\left(\frac{\mathrm{S}_{\mathrm{i}}-\mathrm{S}_{\min }}{\mathrm{S}_{\max }-\mathrm{S}_{\min }}\right)$

Keterangan:

$\mathrm{S}_{\mathrm{i}} \quad=$ Nilai skor aktual pada pengukuran variabel $\mathrm{i}$

$\mathrm{S}_{\max }=$ Skor maksimal

$\mathrm{S}_{\min }=$ Skor minimal

$\mathrm{I}_{\mathrm{i}} \quad=$ Indeks pada variable $\mathrm{i}$

3. Selanjutnya mengalikan indeks yang diperoleh pada setiap variabel dengan bobot masing-masing untuk mendapatkan nilai indeks pada indikator.

$$
\mathrm{X}_{3}=0,33 \mathrm{X}_{31}+0,33 \mathrm{X}_{32}+0,33 \mathrm{X}_{33}
$$

Keterangan:

$\mathrm{X}_{3}=$ Indeks indikator database lembaga zakat

$\mathrm{X}_{31}=$ Indeks variabel jumlah lembaga zakat resmi, muzaki, dan mustahik

$\mathrm{X}_{32}=$ Indeks variabel rasio muzaki individu terhadap jumlah rumah tangga

$\mathrm{X}_{33}=$ Indeks variabel rasio muzaki badan terhadap jumlah badan usaha nasional

4. Tahap selanjutnya adalah mengalikan indeks yang diperoleh pada setiap indikator dengan bobot masing-masing, untuk memperoleh indeks pada dimensi makro. Berikut ini perhitungannya.

$$
\mathrm{X}=0,30 \mathrm{X}_{1}+0,40 \mathrm{X}_{2}+0,30 \mathrm{X}_{3}
$$

Keterangan:

$\mathrm{X}=$ Indeks dimensi makro

$\mathrm{X}_{1}=$ Indeks indikator regulasi

$\mathrm{X}_{2}=$ Indeks indikator dukungan APBD

$\mathrm{X}_{3}=$ Indeks Indikator Database Lembaga Zakat

Nilai dari Indeks Zakat ini dibagi ke dalam lima kriteria, yakni:

a. $0-0,2=$ Tidak baik

b. $0,21-0,4=$ Kurang baik

c. $0,41-0,6=$ Cukup baik

d. $0,61-0,8=$ Baik

e. $0,81-1,0=$ Sangat baik

\section{PEMBAHASAN}

\section{Konsep Zakat}

Secara Bahasa zakat berasal dari kata az-zakā'u yang memiliki arti keberkahan (al-barkatu), pertumbuhan dan perkembangan (al-nama'), kesucian (ath-thaharatu) dan kebaikan (ash-shalahu). Dalam istilah fiqh, 
zakat berarti sebagian dari harta yang wajib dikeluarkan dengan syarat tertentu (Majma'Lughah Al-'Arabiyyah, Al-Mu'jam al Wasith, 1972 : 396). Zakat terbagi menjadi dua jenis, yaitu zakat fitrah dan zakat mal atau zakat harta (As-Sadlan \& Al-Munajjid, 2007). Zakat fitrah merupakan zakat yang wajib dikeluarkan oleh semua muslim yang mempunyai kelebihan nafkah yang wajar pada akhir bulan Ramadhan menjelang Idul Fitri. Besaran zakat fitrah yang dikeluarkan adalah satu sha' atau sekitar $3 \mathrm{~kg}$ berupa makanan pokok yang ada di daerahnya masing-masing (Lajnah Daimah Lil Ifta, Nomor Fatwa 12572).Zakat mal adalah harta yang wajib dikeluarkan oleh setiap muslim atau badan usaha milik muslim yang telah mencapai nisab dan haul, sesuai ketentuan syariat islam. Nisab adalah batas minimal harta yang terkena wajib zakat, dan haul adalah batasan waktu satu tahun hijriyah.

Syarat wajib zakat dilihat dari dua aspek. Pertama dari sisi orang yang wajib mengeluarkan zakat, kedua dari sisi harta sebagai obyek zakat. Menurut Qardhawi (1973) ada beberapa ketentuan atau syarat muzzaki yang harus dipenuhi untuk berzakat, yaitu muslim dewasa yang waras, merdeka dan memiliki kekayaan dalam jumlah tertentu dengan syarat-syarat tertentu. ${ }^{17}$ Dalam pasal 2 Peraturan Menteri Agama Nomor 53 tahun 2014, dijelaskan syarat harta yang dikenakan zakat mal harus milik penuh, halal, cukup nisab dan haul. Sedangkan syarat zakat fitrah adalah beragama islam, hidup saat bulan Ramadhan, dan memiliki kelebihan kebutuhan pokok untuk malam dan hari raya idul fitri. ${ }^{18}$ Dalam Al-Quran surat At-Taubah ayat 60 dijelaskan ada 8 golongan yang wajib menerima zakat yakni fakir, miskin, amil, mualaf, untuk memerdekakan budak belian, gharim, untuk keperluan di jalan Allah, dan orang-orang yang sedang dalam perjalanan. ${ }^{19}$

\section{Perkembangan Regulasi Zakat di Indonesia}

Pada awal abad ke-20, Muhammadiyah (1912) mempelopori tentang pentingnya mengorganisir pengumpulan zakat di kalangan anggotanya. Hingga pada tahun 1964 semasa Menteri Agama K.H. Saifuddin Zuhri, Kementerian Agama menyusun Rancangan Undang-Undang tentang Pelaksanaan Zakat dan Rancangan Peraturan Pemerintah Pengganti Undang-Undang tentang Pelaksanaan Pengumpulan dan Pembagian Zakat serta Pembentukan Baitul Mal.Selanjutnya dikeluarkan Peraturan Menteri Agama Nomor 4 Tahun 1968 tentang Pembentukan Badan Amil Zakat

${ }^{17}$ Yusuf Qardawi, Hukum Zakat, trans. oleh Didin Hafidhuddin dan Hasanuddin, 2 ed. (Jakarta: Intermasa, 1973).

${ }^{18}$ Menteri Agama Republik Indonesia, "Peraturan Menteri Agama Republik Indonesia tentang Syarat dan Tata Cara Penghitungan Zakat Mal dan Zakat Fitrah serta Pendayagunaan Zakat untuk Usaha Produktif" (2014).

19 Al-Quran surat At-Taubah ayat 60. 
dan Peraturan Menteri Agama Nomor 5 tahun 1968 tentang Pembentukan Baitul Mal di tingkat pusat, provinsi, dan kabupaten/kotamadya.

Pemerintah kemudian mengeluarkan Keputusan Presiden Nomor 44 Tahun 1969 tentang Pembentukan Panitia Penggunaan Uang Zakat untukmengelola zakat di bawah koordinasi badan kerohanian Islam pada ruang lingkup pegawai kementerian/lembaga/BUMN. Pada tanggal 5 Desember 1968 BAZIS DKI Jakarta mempelopori pelembagaan zakat ditingkat wilayah, dalam hal ini dibentuk oleh keputusan Gubernur Ali Sadikin. Keberadaan pengelola zakat semi-pemerintah secara nasional dikukuhkan dengan Surat Keputusan Bersama (SKB) Menteri Dalam Negeri dan Menteri Agama No 29 dan No 47 Tahun 1991 tentang Pembinaan BAZIS.

Hingga pada akhirnya Undang-Undang Nomor 38 Tahun 1999 tentang Pengelolaan Zakat lahir di masa Presiden Republik Indonesia ketiga B.J. Habibie dan Menteri Agama H.A. Malik Fadjar. Saat ini UndangUndang Pengelolaan Zakat tahun 1999 diubah dengan Undang-Undang No 23 Tahun 2011 dan diterbitkan Peraturan Pemerintah No 14 Tahun 2014. Pemerintah di masa Presiden Susilo Bambang Yudhoyono menerbitkan Instruksi Presiden No 3 Tahun 2014 tentang Optimalisasi Pengumpulan Zakat di Kementerian/Lembaga, Pemerintah Daerah, BUMN dan BUMD Melalui BAZNAS.

Selanjutnya pada tahun 2015, Menteri Agama mengeluarkan Keputusan Menteri Agama (KMA) No 333/2015 yang menyusun klasifikasi lembaga amil zakat (LAZ) resmi. LAZ ini dibagi menjadi tiga kategori, pertama dikatakan LAZ Nasional jika penghimpunan zakat mencapai Rp50 miliar, kedua LAZ Provinsi jika penghimpunan zakat mencapai Rp20 miliar, terakhir LAZ Kabupaten/Kota jika penghimpunan zakat mencapai Rp 3 miliar. ${ }^{20}$

\section{Konsep Kinerja}

John Whitmore dalam Hamzah (2012) menyebutkan bahwa kinerja adalah pelaksanaan fungsi-fungsi yang dituntut dari seseorang. Pengertian ini merupakan pengertian dari kinerja yang menuntut paling minim untuk berhasil. Kinerja menuntut adanya pengekspresian potensi seseorang, dan tanggungjawab atau kepemilikan yang menyeluruh. ${ }^{21}$

Moeheriono (2012) menjelaskan istilah kinerja dalam kamus Illustrated Oxford Dictionary, diartikan sebagai, "the execution or fulfilment of a duty" 2019).

${ }^{20}$ BAZNAS Center of Strategic Studies, “Outlook Zakat Indonesia 2019” (Jakarta,

${ }^{21}$ Hamzah B Uno dan Nina Lamatenggo, Teori Kinerja dan Pengukurannya (Jakarta: Bumi Aksara, 2012), 60. 
(pelaksanaan atau pencapaian dari suatu tugas). Ia juga menjelaskan tentang kinerja institusi, yakni kinerja yang berkenaan dengan seberapa jauh suatu instansi telah melakukan semua kegiatan pokok sehingga mencapai visi dan misi institusi. ${ }^{22}$

Visi dan misi dalam sebuah instansi zakat sangat penting, karena hal ini dapat menjadi tolak ukur dari kinerja instansi tersebut. Sejauh mana instansi zakat telah mampu menjalankan visi dan misinya. Manajemen kinerja instansi pemerintahan seperti BAZNAS membutuhkan suatu proses sistematis sehingga perlu dibuat desain sistem manajemen kinerja yang tepat untuk mencapai kinerja optimal.

\section{Indeks Zakat Nasional}

Indeks Zakat Nasional (IZN) merupakan sebuah indeks yang disusun oleh Tim Peneliti Pusat Kajian Strategis BAZNAS pada tahun 2016 untuk melihat perkembangan kinerja perzakatan secara nasional. IZN disusun dengan menggunakan pendekatan penelitian berbasis mixed methods. Mixed methodsreaserch merupakan sebuah pendekatan penelitian yang mengombinasikan atau mengasosiasikan bentuk kualitatif dan bentuk kuantitatif. Mentode kualitatif digunakan untuk menyusun komponen pembentuk IZN, sedangkan metode kuantitatif digunakan dalam membentuk model estimasi perhitungannya.

Setelah proses kajian dilakukan, didapatkan komponen-komponen pembentuk IZN yang terbagi menjadi dimensi makro dan dimensi mikro. Selanjutnya kedua dimensi ini dibagi lagi menjadi beberapa komponen yang lebih detail. Dari setiap komponen ini memiliki bobot kontribusi yang telah ditentukan melalui mekanisme FGD dan kriteria expert judgment. Dimensi makro menggambarkan bagaimana peran dari kerjasama antara pemerintah dengan masyarakat secara agregat dalam berkontribusi membangun instansi zakat. Dimensi ini memiliki tiga indikator yaitu, regulasi, dukungan APBD, dan database lembaga zakat. Database lembaga zakat ini kemudian dibagi lagi menjadi tiga bagian, yakni jumlah lembaga zakat resmi, muzaki individu dan muzaki badan usaha.

Secara jelas, berikut ini pengertian dari setiap indikator dan variabel pada dimensi makro, berdasarkan pada panduan IZN PUSKAS BAZNAS dan sumber lainya.

a. Indikator Regulasi

Secara umum, terkait perkembangan regulasi zakat di Indonesia sudah dijelaskan di atas. Namun pada indikator regulasi ini, kita akan membahas

${ }^{22}$ Moeheriono, Indikator Kinerja Utama (IKU): Perencanaan, Aplikasi, dan Pengembangan (Jakarta: Rajawali Press, 2012), 95. 
bagaimana kaitannya dalam pembentukan komponen pada Indeks Zakat Nasional. Indikator regulasi di sini ingin melihat bagaimana Pemerintah beserta DPR/DPRD untuk memberikan perhatian terkait regulasi zakat, baik pada tingkat nasional, provinsi, hingga kabupaten/kota. Dalam pasal 1 ayat 5 UU Nomor 32 Tahun 2004 memungkinkan untuk setiap daerah membuat Peraturan Daerah sesuai dengan keperluannya. ${ }^{23} \mathrm{Hal}$ ini dapat dijadikan dasar bagi setiap daerah untuk membuat Peraturan Daerah Zakat di daerahnya.

Adanya Perda Zakat di setiap daerah, diharapkan dapat meningkatkan penghimpunan zakat secara regional maupun nasional. Selain itu juga, agar pengelolaan dan penyaluran zakat lebih terarah sesuai kebutuhan di daerah itu sendiri. Peraturan daerah ini bersifat lebih kuat daripada sekedar imbuhan kepala daerah. Maka keberadaan Perda ini sangat penting agar lebih mengikat masyarakat untuk mengikuti apa yang menjadi peraturan di daerah, termasuk Perda Zakat untuk membayar zakat sesuai peraturan yang berlaku. Sejalan dengan penelitian Nasrullah (2015) menyatakan bahwa peningkatan penghimpunan zakat berkaitan erat dengan kebijakan pemerintah berupa Peraturan Daerah tentang Zakat. $^{24}$

b. Indikator APBN/APBD

Undang-Undang Nomor 17 Tahun 2003 tentang Keuangan Negara menyebutkan bahwa APBD merupakan rencana keuangan pemerintah daerah yang disetujui oleh Dewan Perwakilan Rakyat Daerah (DPRD) ${ }^{25}$ Tidak jauh berbeda dengan indikator regulasi di atas, adanya indikator APBD disini adalah ingin mengetahui sejauh mana kontribusi pemerintah dan DPRD untuk memperhatikan perzakatan di suatu daerah. Berapa banyak APBD yang disediakan pemerintah untuk membantu operasional lembaga zakat yang ada di Provinsi maupun Kabupaten/Kota.

c. Indikator Database

Indikator database ingin melihat sejauh mana kelengkapan data yang dimiliki oleh lembaga zakat di suatu daerah. Lengkapnya database pada indikator ini bisa dianggap bahwa BAZNAS memiliki administrasi yang baik dan rapi. Selain dari sistem administrasi BAZNAS, indikator ini juga ingin melihat bagaimana peran masyarakat memiliki semangat

23 "UU No. 32 Tahun 2004 tentang Pemerintahan Daerah [JDIH BPK RI]," diakses 20 April 2020, https://peraturan.bpk.go.id/Home/Details/40768/uu-no-32-tahun-2004.

${ }^{24}$ Nasrullah, "Regulasi Zakat dan Penerapan Zakat Produktif Sebagai Penunjang Pemberdayaan Masyarakat (Studi Kasus Pada Baitul Mal Kabupaten Aceh Utara," Inferensi: Jurnal Penelitian Sosial Keagamaan 9(1) (2015).

25 "Undang-Undang UU Nomor 17 Tahun 2003 tanggal 05 April 2003 | JDIH

Kementerian BUMN," diakses 20 April 2020, http://jdih.bumn.go.id/lihat/UU\%20 Nomor\%2017\%20Tahun\%202003.

Kodifikasia: Jurnal Penelitian Islam, Volume, 14 No. 1 Tahun 2020 
untuk menyuburkan perzakatan di daerahnya. Indikator database terbagi menjadi tiga variabel, yakni;

1) Variabel jumlah lembaga zakat resmi, jumlah muzaki, dan mustahik. Variabel ini ingin melihat berapa banyak lembaga zakat, berapa banyak mustahik dan muzaki yang ada di daerah tersebut.

2) Variabel rasio jumlah muzaki individu terdaftar (memiliki NPWZ) terhadap jumlah rumah tangga nasional/daerah. Variabel ini ingin melihat bagaimana kontribusi masyarakat dalam mengembangkan perzakatan dengan cara menjadi muzaki.

3) Variabel rasio jumlah muzaki badan terdaftar (memiliki NPWZ) terhadap jumlah badan usaha. Pada variabel ini ingin melihat bagaimana peran badan usaha yang ada di daerah untuk mengembangkan perzakatan dengan membayar zakat perusahaan.

Selanjutnya gambaran keseluruhan komponen penyusun Indeks Dimensi Makro pada IZN beserta bobot kontribusinya dapat dilihat pada tabel berikut:

Tabel 2.

Bobot Komponen Indeks Dimensi Makro pada Indeks Zakat Nasional

\begin{tabular}{|c|l|c|l|c|}
\hline Dimensi & \multicolumn{1}{|c|}{ Indikator } & $\begin{array}{c}\text { Bobot } \\
\text { Kontribusi }\end{array}$ & \multicolumn{1}{|c|}{ Variabel } & $\begin{array}{c}\text { Bobot } \\
\text { kontribusi }\end{array}$ \\
\hline Makro $(\mathrm{X})$ & Regulasi $\left(\mathrm{X}_{1}\right)$ & 0,30 & Regulasi & 1,00 \\
\cline { 2 - 5 } & $\begin{array}{l}\text { Dukungan } \\
\text { APBN }\left(\mathrm{X}_{2}\right)\end{array}$ & 0,40 & Dukungan APBD & 1,00 \\
\cline { 2 - 5 } & $\begin{array}{l}\text { Database } \\
\text { lembaga zakat } \\
\left(\mathrm{X}_{3}\right)\end{array}$ & 0,30 & $\begin{array}{l}\text { Database jumlah } \\
\text { lembaga zakat } \\
\text { resmi, muzaki, dan } \\
\text { mustahik }\left(\mathrm{X}_{31}\right)\end{array}$ & 0,33 \\
& $\begin{array}{l}\text { Rasio Muzaki } \\
\text { Individu (X }\end{array}$ & 0,33 \\
\hline $\begin{array}{l}\text { Rasio Muzaki Badan } \\
\left(\mathrm{X}_{33}\right)\end{array}$ & 0,33 \\
\hline
\end{tabular}

Sumber: Data diolah peneliti dari PUUSKAS BAZNAS, 2019.

Teknik estimasi penghitungan yang dilakukan dalam memperoleh nilai IZN menggunakan metode yang dinamakan Multistage Weighted Index. Metode ini menggabungkan beberapa proses tahapan pembobotan yang telah diberikan pada setiap komponen penyusun indeks, sehingga pembobotan yang diberikan pada setiap komponen harus dilakukan secara bertahap dan bersifat prosedural. Proses pembobotan dilakuukan setelah mendapatkan indeks yang dihitung pada setiap variable, dengan mengikuti rumus berikut: 


$$
\mathrm{I}_{\mathrm{i}}=\left(\frac{\mathrm{S}_{\mathrm{i}}-\mathrm{S}_{\min }}{\mathrm{S}_{\max }-\mathrm{S}_{\min }}\right)
$$

Keterangan:

$\mathrm{S}_{\mathrm{i}} \quad=$ Nilai skor aktual pada pengukuran variabel $\mathrm{i}$

$\mathrm{S}_{\max }=$ Skor maksimal

$\mathrm{S}_{\min }=$ Skor minimal

$\mathrm{I}_{\mathrm{i}} \quad=$ Indeks pada variable $\mathrm{i}$

Skor aktual diberikan berdasarkan keadaan real yang terjadi di lapangan, berdasarkan standar yang sudah ditentukan oleh PUSKAS BAZNAS. Nilai indeks yang dihasilkan akan berada pada rentang 0,00-1,00. Ini berarti semakin rendah nilai indeks yang didapatkan maka semakin buruk kinerja perzakatan nasional, dan semakin besar nilai indeks yang diperoleh makan semakin baik kondisi perzakatan. Formulasi perhitungan IZN ini diharapkan dapat menjadi pengukuran standar kinerja zakat nasional yang diukur secara periodik (misalkan setiap tahun) sehingga evaluasi dilakukan secara berkelanjutan.

Selain pada tingkat nasional, perhitungan IZN juga dapat dilakukan pada tingkat regional provinsi sehingga perbandingan antara daerah, dan setiap komponen pembentuknya seperti pada bagian kelembagaan, perhitungan indeks juga dapat dilakukan secara terpisah sehingga penerapannya bisa dilakukan di organisasi-organisasi pengelola zakat baik di tingkat pusat hingga tingkat daerah. Hal ini bertujuan agar semua pihak dalam perzakatan dapat mengukur diri sekaligus meningkatkan diri terkait kinerja zakat, serta peningkatan pemahaman publik terhadap kontribusi zakat bagi Indonesia.

Berikut ini hasil dari perhitungan indeks dimensi makro pada BAZNAS Kota Mataram berdasarkan Indeks Zakat Nasional.

1. Indikator Regulasi $\left(\mathrm{X}_{1}\right)$

Pemerintah Kota Mataram mengeluarkan Peraturan Daerah Nomor 1 tahun 2015 tentang Pengelolaan Zakat, Infaq dan Sedekah (ZIS), guna meningkatkan penghimpunan dana ZIS yang ada di Kota Mataram. Indikator regulasi, jika suatu Kabupaten/Kota memiliki Perda Pengelolaan Zakat akan diberikan skor 5 yang masuk kategori kuat. Selanjutnya nilai indeksnya adalah 1 yang berarti kinerja pada indikator regulasi ini adalah sangat baik.

2. Indikator Dukungan APBD $\left(\mathrm{X}_{2}\right)$

Pemerintah Kota Mataram pada tahun 2018 mengucurkan dana sebesar Rp 2,1 miliar untuk BAZNAS Kota Mataram. Rp 1,5 miliar dalam bentuk beras untuk kegiatan santunan lansia terlantar, dan Rp 600 
juta untuk biaya operasional BAZNAS Kota Mataram. Pada Laporan Perubahan Dana Amil (BAZNAS Kota Mataram, 2018), terdapat pengeluaran sebesar Rp 2,9 miliar. Angkat tersebut terbagi ke dalam beberapa kategori. Rp 1,5 miliar untuk pengadaan beras bagi lansia, $\mathrm{Rp}$ 7 juta untuk bantuan kemanusiaan, dan sisanya Rp 1,393 miliar untuk biaya operasional selama 2018. Dari angka tersebut terlihat bahwa total alokasi APBD terhadap operasional BAZNAS Kota Mataram adalah sebesar 43\%. Maka indicator ini mendapatkan skor 3 karena memiliki rasio total alokasi APBD terhadap biaya operasional lebih dari 30\%. Nilai indeks dari indikator dukungan APBD adalah 0,5 yang berarti kinerjanya adalah baik.

3. Indikator Database $\left(\mathrm{X}_{3}\right)$

Secara keseluruhan, indeks indikator database mendapatkan nilai indeks 0,33, yang berarti kinerja pada indikator database adalah baik. Berikut ini penjabaran nilai indeks setiap variabel pada indikator database.

a. Variabel database jumlah lembaga zakat resmi, database muzaki, dan mustahik perlembaga $\left(\mathrm{X}_{31}\right)$, mendapatkian skor 3 yang berarti kuat. Nilai indeksnya adalah 0,5 yang berarti kinerja BAZNAS Kota Mataram cukup baik pada variabel database jumlah lembaga zakat resmi, muzaki dan mustahik. Di Kota Mataram hanya da BAZNAS Kota Mataram yang terdaftar sebagai lembaga pengelola zakat di Kota Mataram, dan BAZNAS Kota Mataram memiliki data terkait muzaki dan mustahik di lembaganya.

b. Rasio jumlah muzaki individu terhadap jumlah rumah tangga kabupaten/Kota $\left(\mathrm{X}_{32}\right)$. Pada variabel ini BAZNAS Kota Mataram mendapatkan skor 3 yang berarti rasio jumlah muzaki individu terhadap jumlah rumah tangga adalah 4,24\%. Nilai indeksnya sendiri adalah 0,5 yang berarti cukup baik.

c. Rasio jumlah muzaki badan terhadap badan usaha di Kabupaten/Kota $\left(\mathrm{X}_{33}\right)$. Pada BAZNAS Kota Mataram hanya terdaftar 1 badan usaha, sedangkan jumlah industry formal adalah 2.172 badan usaha. Maka rasionya adalah $0,046 \%$ yang berarti mendapatkan skor 1 dengan kategori kuat, dan mendapat nilai indeks 0 yang berarti kinerja pada variabel ini adalah tidak baik.

Setelah setiap indeks variabel dan indikator diketahui, tahap selanjutnya adalah menghitung indeks dimensi makro. Pada dimensi makro didapatkan nilai indeks sebesar 0,599. Kinerja BAZNAS Kota Mataram pada dimensi makro ini berarti cukup baik. Dapat dilihat bahwa BAZNAS Kota Mataram sudah memiliki Perda Zakat, mendapatkan dukungan APBD dari 
Pemerintah, rasio muzaki individu terhadap rumah tangga sebesar 4,24\% dan rasio muzaki badan terhadap badan usaha adalah 0,046\%.

\section{PENUTUP}

\section{Kesimpulan}

Kinerja BAZNAS Kota Mataram berdasarkan indeks dimensi makro pada Indeks Zakat Nasional adalah cukup baik dengan nilai indeks dimensi makro 0,599. Nilai tertinggi terdapat pada indeks indikator regulasi dengan nilai indeks 1 yang berarti kinerja pada indikator ini sangat baik. Indeks tertinggi kedua pada indikator dukungan APBD dengan nilai indeks 0,5 yang berarti kinerja pada indikator ini cukup baik. Rasio APBD terhadap biaya operasional BAZNAS Kota Mataram adalah 43\%. Dan terakhir adalah indeks indikator database dengan nilai indeks 0,33.

Adapun saran kepada Pemerintah Kota Mataram, sebaiknya Perda Zakat di Kota Mataram lebih dioptimalkan lagi, karena banyak masyarakat yang belum mengetahui terkait Perda tersebut, yang mengetahui hanya pada kalangan tertentu seperti pegawai OPD, dan guru PNS. Perlu adanya peran penting dari pemerintah dan lembaga zakat, untuk lebih giat melakukan sosialisasi terkait penting dan wajibnya membayar zakat melalui kegiatan Zakat Festival atau Zakat Fair dan sejenisnya.

Selanjutnya bagi BAZNAS Kota Mataram, perlu adanya peningkatan sistem publikasi informasi atau website BAZNAS Kota Mataram. Agar kedepannya muzaki lebih mengetahui informasi terkait kegiatan di BAZNAS Kota Mataram dan alokasi dana yang mereka salurkan. Terakhir kepada pihak PUSKAS BAZNAS, perlu adanya penjelasan prosedur dalam proses penghitungan Indeks Zakat Nasional secara umum dan pada tingkat kabupaten/kota, karena Indeks Zakat Nasional merupakan alat ukur kinerja perzakatan yang masih baru. 


\section{DAFTAR RUJUKAN}

Badan Pusat Statistik Kota Mataram. "PDRB atas Dasar Harga Berlaku 2010-2016." Mataram, 2017. https://mataramkota.bps.go.id/ dynamictable/2017/07/05/298/pdrb-kota-mataram-atas-dasar-hargakonstan-2010-menurut-lapangan-usaha-2010-2016.html.

BAZNAS Center of Strategic Studies. "Outlook Zakat Indonesia 2019." Jakarta, 2019.

Dinas Komunikasi dan Informatika Kota Mataram. "Kota Mataram dalam Data 2018." Mataram, 2018.

Farchatunnisa, Hidayaneu. "Analisis Kinerja Baznas Kota Bandung Dengan Pendekatan Indeks Zakat Nasional.” IPB Bandung, 2017.

Hilmiyah, Ulfah Laelatul. "Analisis Kinerja Perzakatan BAZNAS Kabupaten Bogor." IPB Bogor, 2017.

Khoirunnisa, Ayu Amalia. "Analisis Kinerja Baznas Kabupaten Cilacap Dengan Pendekatan Indeks Zakat Nasional." IPB Bogor, n.d.

Menteri Agama Republik Indonesia. Peraturan Menteri Agama Republik Indonesia tentang Syarat dan Tata Cara Penghitungan Zakat Mal dan Zakat Fitrah serta Pendayagunaan Zakat untuk Usaha Produktif (2014).

Moeheriono. Indikator Kinerja Utama (IKU): Perencanaan, Aplikasi, dan Pengembangan. Jakarta: Rajawali Press, 2012.

Nasrullah. "Regulasi Zakat dan Penerapan Zakat Produktif Sebagai Penunjang Pemberdayaan Masyarakat (Studi Kasus Pada Baitul Mal Kabupaten Aceh Utara." Inferensi: Jurnal Penelitian Sosial Keagamaan 9(1) (2015).

Pusat Kajian Strategis Badan Amil Zakat Nasional. "Indeks Zakat Nasional.” Jakarta, 2016. http://puskasbaznas.com/indonesia-zakatindex/national-zakat-index/nzi/download/70-nzi.

Qardawi, Yusuf. Hukum Zakat. Diterjemahkan oleh Didin Hafidhuddin dan Hasanuddin. 2 ed. Jakarta: Intermasa, 1973.

Uno, Hamzah B, dan Nina Lamatenggo. Teori Kinerja dan Pengukurannya. Jakarta: Bumi Aksara, 2012. 
212 | Ahmad Sidi Pratomo, Shulhan Zainul Afkar

Widiawati, Nunung Nurhayati, dan Ifa Hanifa Senjiati. "Kinerja Pengelolaan Zakat Menggunakan Indeks Zakat Nasional (IZN) di Baznas Provinsi Jawa Barat." Prosiding Hukum Ekonomi Syariah 4(1) (2018): 308-14. 


\section{AUTHOR GUIDELINES}

Kodifikasia: Jurnal Penelitian Islam hanya menerima naskah yang ditulis dalam Bahasa Indonesia dan/atau Bahasa Inggris. Berikut ini adalah pedoman kami sebagai bagian dari proses pengiriman untuk memastikan naskah anda sesuai dengan persyaratan jurnal.

1. Penulis harus memastikan tulisannya sesuai dengan artikel template Kodifikasia: Jurnal Penelitian Islam

2. Naskah belum pernah diterbitkan sebelumnya, atau telah dipertimbangkan dalam jurnal lain.

3. File naskah dalam format Microsoft Word (.doc).

4. Mengenai bibliografi/referensi, Kodifikasia: Jurnal Penelitian Islam menerapkan Chicago Manual Style (full note). Oleh karena itu, kami berharap penulis memperhatikannya dan sangat dianjurkan bagi penulis untuk menggunakan sarana manajer referensi seperti Zotero, Mendeley atau lainnya

\section{Style Selingkung Kodifikasia: Jurnal Penelitian Islam}

1. Naskah adalah hasil penelitian otentik yang belum dipublikasikan di media publikasi lain atau penerbit.

2. Naskah tidak mengandung unsur plagiarism (toleransi maksimal 25 $\%)$. Dewan editorial akan menolak teks yang melebihi batas maksimal toleransi plagiarisme.

3. Naskah yang telah ditulis sesuai pedoman Kodifikasia: Jurnal Penelitian Islam, (dalam format MS Word, sesuai template artikel) harus diserahkan melalui Sistem Pengajuan Online menggunakan Open Journal System (OJS), pada alamat: https://jurnal.iainponorogo.ac.id/ index.php/kodifikasia/about/submissions

4. Naskah yang tidak sesuai dengan template Kodifikasia: Jurnal Penelitian Islam akan dikembalikan kepada penulis sebelum proses peninjauan atau review.

5. Naskah dapat ditulis dalam Bahasa Indonesia atau Bahasa Inggris dengan bahasa standar akademik.

6. Naskah harus terdiri dari 4000 hingga 6000 kata termasuk gambar dan tabel.

7. Naskah ditulis pada kertas berukuran A4 (210x297 mm), dengan margin khusus sebagai berikut: kiri $25 \mathrm{~mm}$, kanan $20 \mathrm{~mm}$, bawah 20 $\mathrm{mm}$, dan atas $30 \mathrm{~mm}$.

8. Kata-kata dari bahasa asing dinyatakan dalam format Italic. 
9. Setiap paragraf dimulai $10 \mathrm{~mm}$ dari perbatasan sisi kiri dan tidak ada spasi di antara paragraf.

10. Semua angka ditulis dalam format penomoran Arab, kecuali untuk kalimat baru.

11. Tabel dan gambar ditempatkan dalam grup teks setelah tabel atau gambar yang direferensikan. Setiap gambar harus diberi keterangan (Gambar Keterangan) di bawah gambar dan diberi nomor dalam format penomoran Arab diikuti dengan judul gambar. Setiap tabel harus diberi judul tabel (Keterangan Tabel) dan diberi nomor dalam format penomoran Arab di atas tabel diikuti dengan judul tabel.

12. Lampiran gambar harus dijamin dapat dicetak dengan baik (ukuran font, resolusi, dan ruang garis terlihat jelas).

13. Semua kutipan dalam artikel menggunakan referensi catatan kaki. 